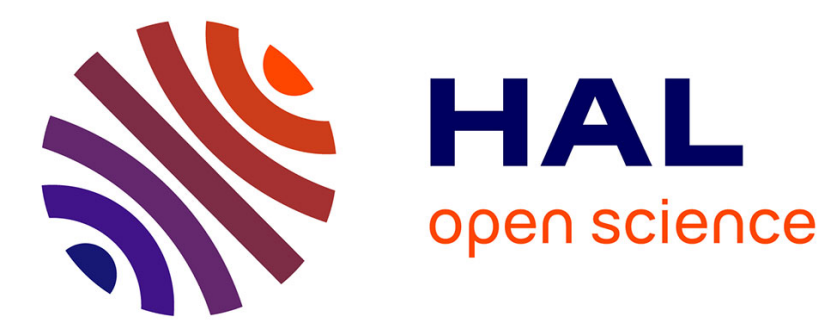

\title{
Human-Centric Manufacturing Workplaces: Aiming at Increasing Attractiveness and User Experience
}

\author{
Paola Fantini, Marta Pinzone, Marco Taisch, Jaume Altesa
}

\section{To cite this version:}

Paola Fantini, Marta Pinzone, Marco Taisch, Jaume Altesa. Human-Centric Manufacturing Workplaces: Aiming at Increasing Attractiveness and User Experience. IFIP International Conference on Advances in Production Management Systems (APMS), Sep 2016, Iguassu Falls, Brazil. pp.363-370, 10.1007/978-3-319-51133-7_43 . hal-01615802

\section{HAL Id: hal-01615802 \\ https://hal.inria.fr/hal-01615802}

Submitted on 12 Oct 2017

HAL is a multi-disciplinary open access archive for the deposit and dissemination of scientific research documents, whether they are published or not. The documents may come from teaching and research institutions in France or abroad, or from public or private research centers.
L'archive ouverte pluridisciplinaire HAL, est destinée au dépôt et à la diffusion de documents scientifiques de niveau recherche, publiés ou non, émanant des établissements d'enseignement et de recherche français ou étrangers, des laboratoires publics ou privés.

\section{(c)(1)}

Distributed under a Creative Commons Attribution| 4.0 International License 


\title{
Human-Centric Manufacturing Workplaces: Aiming at Increasing Attractiveness and User Experience
}

\author{
Paola Fantini $^{1 *}$, Marta Pinzone ${ }^{1}$, Marco Taisch $^{1}$, Jaume Altesa $^{2}$ \\ ${ }^{1}$ Politecnico di Milano, Department of Management, Economics and Industrial \\ Engineering, Milan, Italy \\ \{paola.fantini, marta.pinzone, marco.taisch\}@polimi.it \\ ${ }^{2}$ Alstom Transporte SA, Santa Perpetua de Mogada, Barcelona, Spain \\ jaume.altesa-cabanas@transport.alstom.com
}

\begin{abstract}
The pursuit of Human-Centric Manufacturing Workplaces is one of the strategic objectives of the industrial and academic research community, as a contribution to the creation of sustainable and attractive jobs in production. The concepts of User experience (UX), Interactive Virtual Prototyping (VP) and the connected scientific background can lead to new perspectives and methods for the design and evaluation of future workstations. The traditional focus on productivity and ergonomics, might be extended to encompass multisensory features and to consider the different usage stages in order to improve the experience of the workers and contribute to enhance the attractiveness of manufacturing workplaces. The application case of a train manufacturer's is taken to exemplify possible results of the application of this UX and VP-inspired approach to the design of Human-Centric Manufacturing Workplaces.
\end{abstract}

Keywords: Manufacturing · User experience $\cdot$ Workplaces

\section{$1 \quad$ Manufacturing Jobs and Workplaces}

The manufacturing industry plays an important role in the European economy in terms of GDP (16\% of EU GDP) and employment (30 millions).

Although currently decreasing, unemployment is a major concern in Europe: Eurostat estimates that 23.887 million men and women in the EU-28 were unemployed in February 2015 of which 4.850 million young persons (under 25 [1]). Interestingly, in spite of the high level of unemployment, manufacturers find difficulties in filling jobs $[2,3,4,5]$.

As a consequence, attracting skilled workers is becoming one of the top priorities for industrial companies and the creation of socially sustainable, safe and appealing workplaces is among the main objectives of the strategic multi-annual research roadmap produced by the European Factory of the Future Research Association [6]. 


\section{Motivation for Human-Centric Manufacturing Workplaces (HCMW)}

The emphasis on Human-Centric Manufacturing Workplaces (HCMW) derives from different objectives and needs. The adaptation of work demands to the physical and cognitive capabilities of the workers, especially for older operators and disabled people [6] is required to increase manufacturing performances - flexibility, agility, and competitiveness - by leveraging the full potential and the experience of each individual. There is also an emerging value orientation towards considering workers' wellbeing in manufacturing settings, besides considering the pure execution of tasks [7] and towards motivating potential employees, especially young people, to even consider working in the factories. Furthermore, there is recognition that workplaces must evolve in relationship to technological and organizational changes and taking into account the needs of employees to balance privacy, collaboration and work objectives [8].

\section{Design Concepts}

Human-centric and personalized work design has been so far addressed mostly with the aim of adapting the geometry, the functional demand, the knowledge and skills requirements, besides the occupational health and safety aspects, failing to consider the complexity of the interaction between human beings and their environment. There is in fact a continuous and dynamic interaction between employees and their workspace, encompassing light, temperature, noise, vibrations, gases and particulates in the air, pressure, etc. which generates physiological and psychological effects on the workers. [9].

Industrial firms, confronted with the challenge of filling the skills gaps by attracting young people to manufacturing jobs and improving the workers' wellbeing, should elaborate new approaches to the design of jobs and workstations aiming at improving the individual experience, taking into account inter-individual differences (gender, anthropometrics) and intra-individual differences (physicological and psycological states) [9], instead of statistic data referred to a population of employees.

Design of consumers goods might provide inspiration and lesson learnt transferable to the industrial design. If the aim is creating attractive workplaces, the workers should not be considered only as users, but should be equated to customers. Research on interactive products has mainly focused on functionalities, but an increasing attention has been recently given to the user experience (UX), as the notion of capturing the wide variety and emerging effects of technology in use, including emotional, affective and experiential factors [10]. The HCMW design should therefore focus on the user experience (UX) of the workers and on the perceived value, that encompasses different aspects, such as innovativeness, customization, usability, coolness and the emotional content.

Studies have referred to sensory modalities and to time as relevant dimension of anaysis on user-product interaction (i.e. [12,13]).

In fact, if consumers' experience with products is always multisensory [12], the concept can easily be extended to workers interaction with their workplace. To the knowledge of the authors, there are no studies on the experience of the workers with 
the workstation that take into account emotions, aesthetics, and symbolism. However, potentially, there seem to be similarities and differences between the interactions that workers experience with their equipment and tools, and those that the consumers live with certain types of goods. For instance, within the consumers' products analysed [12], some home appliances or even vehicles can be considered as tools to perform some tasks and therefore can be assimilated to industrial equipment and tools, at least to some extent. Home appliances such as coffee maker or washing machines or even vehicles, for example, have been analysed under the perspective of sensorial dominance and usage stage. Findings show that vision is the most important modality at the beginning, but after one week of usage other modalities gain increasing relevance [12], in particular touch and audition.

The design of user experience, and of multisensory user experience, is acquiring increasing recognition not only for computer-based systems but for any kind of system users interact with [14].

Among the different methods and tools available in order to integrate user experience concern in the design phase of products, VP appear as extremely valuable. Virtual prototypes, equipped to recreate all the senses actually involved in the real interaction, can in fact enable capturing the UX from the users during the system design, before building the physical system [14]. In some cases also complex simulations Human in the Loop can support the prediction of UX, but they require the existence and availability of human models incorporating interaction behaviour [15].

\section{Pursuing Attractiveness and User Experience in HCMW}

The stimuli and the concepts of the Interactive Virtual Prototyping lead to considering an extension of the perspective adopted to design HCMW with the aim of improving the attractiveness of manufacturing jobs. In particular, the traditional perspective of focusing on productivity and ergonomics could be enhanced by integrating two additional perspectives considering the time dimensions along the usage stages and the multisensory dimension of user experience.

\subsection{Productivity and Ergonomics}

Workspace design obviously needs to leverage all the pre-existing knowledge accumulated especially with reference to assembly lines, within manufacturing systems. Available frameworks and methodologies consider technological as well as environmental variables to design and optimize productivity and ergonomics (i.e. [17]).

In particular, workplace design include the definition of the geometrical disposition of the working area, the place were the parts are placed for picking with respect to the worker location and posture has to be defined Furthermore the level of physical or cognitive automation provided through supporting devices such i.e. lifting or motorized wire carousel devices or such as displays, "wearables" etc.

This aspects have been extensively studied to pursue workers health, safety and wellbeing but without addressing more hedonistic and emotional characteristics that may influence workers experience and thus workplaces attractiveness. 


\subsection{Usage Stages}

The literature on user experience with consumers' goods has identified significant stages on the time dimension that, depending on the specific goods, may be: the first encounter, the purchase, the first use, the use in the first week, etc.

Concerning workstations, the time dimension can be considered as characterized by the following stages:

- acquaintance. This corresponds to the "getting familiar" stage [13], in which the users get to know the workstation for the first time and receive the first impressions. The pre-purchase and buying stages are out of this scope as undertaken by organizational roles other than the workers;

- configuration/personalization. This stage, which is not always meaningful for consumers goods, is relevant for workstations with personalization features;

- usage/operation. This stage can be subdivided in periods to capture the different user-product interaction patterns that usually shift in time, as for sensorial dominance [12];

- end-of-shift resetting. This stage may be required for shared goods. In manufacturing systems, workers' assignment to the workstations changes according to the shifts, job rotation mechanisms and other issues. According to the degree of personalization implemented, it might be convenient to incorporate a resetting functionality. As an alternative, the configuration/personalization might directly overwrite any previous setting.

\subsection{Sensorial Experience}

The influence of the sensorial characteristics on user experience have been analysed with reference to consumers' goods and attributes that produce positive effects have been identified, however the overall feeling of pleasantness of a good seems to be quite difficult to predict and therefore to define guideline for design [16]

The difficulty seems due to the complex combinations of stimuli [18] and sensorial experiences and to situational variables, symbolic meanings, as well as the impact of cognitive beliefs and expectations [16].

Workplaces differ from consumers' goods under several perspectives, and are subject to several constraints related to productivity and ergonomics, different standards and norms. Furthermore they are permeated with meanings related to the work and social context.

Finally they imply a long term, recurring, regulated interaction with the users.

Research on HCMW might potentially highly benefit from the lesson learnt of consumers' goods to encompass the usage stage and multisensory dimensions.

IVP could support the design of workplaces and allow quick and affordable acquisition of the users' feedback, although the development of human model would be needed in order to predict the workers' interaction and experience along the different stages of usage. 


\section{HCMW Design Application Case}

\subsection{Productivity and Ergonomic}

Research on human-centric workplaces [19] has addressed a case taken from the train manufacturing process: the vertical wiring mock-up, which consists in the preparation of the electrical wires prior to their installation in the trains. The preparation job requires several hours and is performed in the electrical department of the manufacturer. The current workplace is illustrated in the picture on the left in Erro! Fonte de referência não encontrada. 1 .

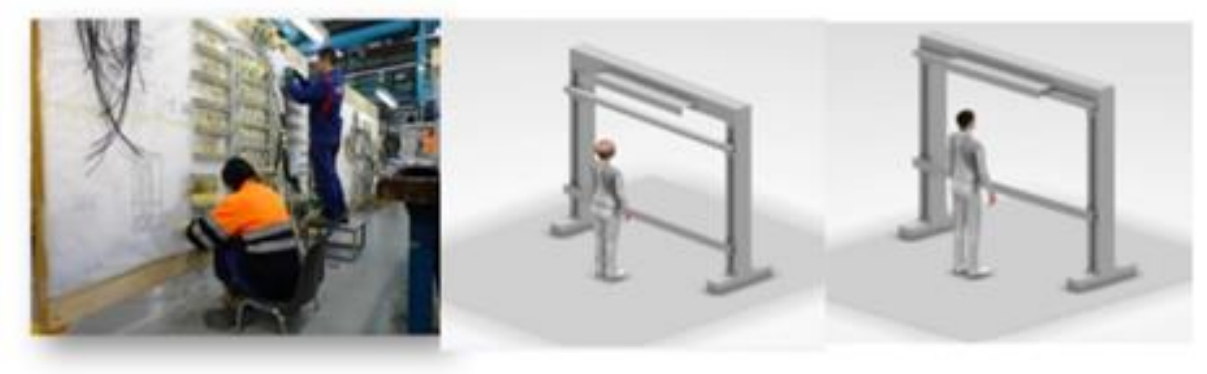

Fig. 1. Current workplace

The human-centric approach has led the to re-designing these workplaces with novel equipment adjustable according to the morphologic characteristics of each individual worker, as illustrated in the central and right pictures of the figure.

This result, developed in a FP7 funded research [20], represents a significant advancement with reference to the AS IS situation and to design ergonomics, as it allows taking into account individual characteristics of the workers.

\subsection{Exploring Multi-sensorial and Lifecycle Oriented Re-design}

Identification of additional features to workplace re-design. The human-centric redesign of the workplace described in 5.1 might be enhanced by leveraging the knowledge, methods and tools developed in the field of virtual prototyping and user experience for consumers' goods.

In particular, a proposal to extend the perspective to HCMW design by leveraging the multisensory and usage-phase related concepts stimulate design research to explore additional features for the workstation to be validated through VP.

As an example, through VP it would be possible to predict the interaction and acquire workers' feedback with reference to different design options addressing the configuration/personalization phase of the workstation: different types of vertical adjustment mechanisms with associated friction, visual, acoustic and/or haptic feedback to guide upward or downward the vertical movement and to signal the achievement of the correct position etc. 
Similarly, through VP it would be possible to evaluate and validate alternative design solutions with reference to the usage/operation phase. Possible examples may include for example equipping the workstation with auxiliary devices to rule the local lighting (intensity, orientation, colour), the heating/cooling, or to create a pleasant soundscape and -why not? - aromatic odour waves. Furthermore, multisensory stimuli could be possibly associated to the completion of individual tasks or work phases in order to provide feedback to the worker and underline the progress of his/her work.

Initial validation of concepts and features. The concepts developed and the design features preliminary identified ground on the assumptions that making workplace more attractive is becoming a priority for industrial enterprises and that theories and techniques can be derived from the design of consumers' goods and applied in manufacturing environments in order to improve the user experience of the operators. Before going further in the development of these notions, it is therefore important to start a validation process with the relevant stakeholders. In the case of the of the train manufactures, three main roles were identified to this purpose: the Engineer in charge of the design, the Production Manager and the Operator. For each role, a representative, all involved in the design or management or operations of vertical mock-up, with more than five years experience in the role were selected to be confronted with a set of questions aiming at understanding the alignment of the goal of making the working experience more enjoyable with the objectives of their roles; the relevance of the identified concepts; the relative importance of the workplace lifecycle phases and of the multi-sensorial features; and finally, to what extent the results of the proposed approach are perceived as relevant in comparison with other possible interventions, such as social networks or smart devices to support the operators during their work.

Results. The orientation of the company, as perceived by the representatives of the different roles, seems to prioritize safety and ergonomics objectives overall; productivity, workers well being and flexibility appear to be important for all the roles, capital expenditure and operational expenditure only for the Production Manager, and work pleasantness important for the Operator, very important for the Production Manager and not important for the Engineer.

The human centric re-design is considered as more beneficial for the company and for the workers than the use of wearable equipment by the Engineer and Production Manager, but not at all by the Operator.

The importance of all the phases of the workplace lifecycle is equally important for the Production Manager, and for the Operator, but for the resetting, which is considered as not really important by the latter. The Engineer however has a clear ladder of decreasing significance from the initial phase of acquaintance, to the usage, to the configuration and finally to the resetting.

The appreciation of the multi-sensorial features proposed appears to favour the Lightening and HVAC personalization. Sound design appears to be considered important only by the Engineer, while the tactile features are disregarded. The evaluation of the Operator in particular sharply distinguishes between these two characteristics as very important and the others as not important at all. 
Finally, the Human centric re-design of the workplace as a whole is considered more important than the availability of smart devices. However, the Operator would rather prefer the availability of social networks.

Overall these results appear to confirm the relevance of the human-centric re-design of the workplace, and of some multi- sensorial features. However, there is no clear indication about the significance of the different phases of the lifecycle and for sound and tactile design features, as shortly described.

\section{Conclusions}

The design of Human-Centric Manufacturing Workplaces may potentially benefit from the lesson learnt in the design of consumers' goods. In principle, the traditional perspective on the design of industrial goods might be extended to create attractive workplaces. A preliminary attempt to apply this comprehensive perspective to the application case of a vertical mock up wiring workstation for a train manufacturer seems to lead to interesting, unexplored possibilities. The preliminary results supports only the relevance of the matter and do not provide indications or confirm that enhancing the design methods with lifecycle consideration and tactile and sound characteristics is valuable. However these preliminary results suffer from the limitation of using short verbal descriptions to propose the different design alternatives to the stakeholders. An avenue for future research could stem from the use of VP to better capturing the feedback of the operators and other actors in the interaction with alternative design options, as suggested by the VP literature.

\section{References}

1. Eurostat Statistics: Explained - Unemployment statistics, http://ec.europa.eu/eurostat/statistics explained/index.php/Unemployment_statistics

2. Accenture, Manufacturing Institute.: Accenture 2014 Manufacturing Skills and Training Stdy - Out of Inventory Skills Shortage Threatens Growth for US Manufacturing (2014)

3. Deloitte, The Manufacturing Institute. The Skills Gap in U.S. Manufacturing (2015)

4. Deloitte, The Manufacturing Institute.: Bolining Point? The Skills Gap in U.S. Manufacturing (2011)

5. World Economic Forum: Matching Skills and Labour Market Needs - Building Social Partnerships for Better Skills and Better Jobs (2014)

6. EFFRA: Factories of the Future PPP - FoF20220 Roadmap - Consultation document. Bruxelles (2012)

7. Profita, H., Lim, A., Brinkman, D., Smith, R.: Wall Relief: Ahealth-Oriented Interactive Installation for the Workplace Environment. TEI. Standford, CA, USA (2015)

8. Young Lee, S., Brand, J.: Effects of Control Over Office Workspace on Perceptions of the Work Environment and Work Outcome. Journal of Environmental Psychology , 25, 323333 (2005)

9. Parsons , K.: Environmental Ergonomics: A Review of Principles, Methods and Models. Applied Ergonomics, 31, 581-594 (2000) 
10. Chong-Leng Goh, J., Faezeh, K.: Towards the Development of a 'User-Experience' Technology Adoption Model for the Interactive Mobile Technology. HCIB/HCII 2014, 620-630 (2014)

11. Cugini, U.: Virtual Prototypes and Real Products. Virtual Prototyping Summer School 2015 - PPT Presentation (2015)

12. Fenko, A., Schifferstein, H. N.: Shifts in Sensory Dominance between Various Stages of User-product interactions. Applied Ergonomics, 41, 34-40 (2009)

13. Chen, N.-f., Ho, C.-H., Ma, M.-Y.: Sensory Importance and Emotions at Early Stage of Product Experiences - A qualitative Study of Jiuce Squeezer. Departent of Industrial Design, National Cheng Kung University - Tainan City - Taiwan (2009)

14. Ferrise, F., Furtado, G., Graziosi, S., Bordegoni, M.: Digitalizing and Capturing Haptic feedback in Virtual Prototypes for User Experience Design. IEEE (2013)

15. Filippi, S., Barattin, D., Ferrise, F., Bordegoni, M.: Human in the Loop: A Model to Integrate Interaction Issues in Complex Simulations. DUXU/HCU (2013)

16. Fenko, A., Schifferstein, H. N.: The Influence of Sensory Product Properties on Affective and Symbolic Product Experience. Proceedings off 8th International Design and Emotion Conference. London (2012)

17. Battini, D., Faccio, M., Persona, A., Sgarbossa, F.: New Methodological Framework to Improve Productivity and Ergonomics. International Journal of Industrial Ergonomics, 41, 30-42 (2011)

18. Liberati, D., Bedarida, L., Brandazza, P., Cerutti, S.: A model for the Cortico-cortical Neural Interaction in Multisensory-evoked Potentials. IEEE Transactions on Biomedical Engineering , 38 (9) (1991)

19. MAN-MADE.: D1.3 Validation Scenarios Definition. Manufacturing through Ergonomic Safe and Anthropocentric Adaptative Workplaces (2014)

20. MAN-MADE Project.: http://www.man-made.eu/. From MAN-MADE Project. 